\title{
STATUS ATUAL DAS PESQUISAS COM COMUNIDADES TRADICIONAIS NO SEMIÁRIDO
}

Sandra Valéria Silva Lins¹; Ioná Pereira da Silva²; Cláudio Roberto Borges Oliveira; Carlos Alberto Batista Santos ${ }^{3}$

${ }^{1}$ Bacharel em Direito, Licenciada em Ciências Sociais, Mestranda no Programa de Pós Graduação em Ecologia Humana e Gestão Socioambiental (PPGEcoH), da Universidade do Estado da Bahia (UNEB), Bahia, Brasil.

${ }^{2}$ Mestrandos no Programa de Pós Graduação em Ecologia Humana e Gestão Socioambiental (PPGEcoH), da Universidade do Estado da Bahia (UNEB) ${ }^{3}$ Universidade do Estado da Bahia. Dr. em Etnobiologia e Conservação da Natureza. Docente PPGEcoH. cacobatista@yahoo.com.br

\section{Recebido em: 06/04/2019 - Aprovado em: 10/06/2019 - Publicado em: 30/06/2019} DOI: 10.18677/EnciBio_2019A192

\begin{abstract}
RESUMO
Este artigo discute o status atual das pesquisas desenvolvidas a partir dos saberes e fazeres das comunidades tradicionais no semiárido, com foco nos povos indígenas, povos de terreiros e pescadores artesanais. levando-se em consideração que a região semiárida do Nordeste brasileiro tem características ambientais que impõe sérias limitações no processo produtivo dessas populações, exigindo-se delas uma capacidade de adaptação a esse meio, propostas como essa visam identificar quais os aspectos socioeconômicos, culturais e ambientais mais investigados e aqueles que necessitam de atenção e intervenção por parte dos centros de pesquisa e apoio, com vistas a apoiar e orientar os processos produtivos nestas comunidades. A pesquisa foi realizada em sites de pesquisas acadêmicos, google scholar e Science direct e Scielo, utilizando-se indexadores selecionados previamente. As pesquisas atuais sobre os povos tradicionais no semiárido, são bem significativas, de boa qualidade, fomentando programas de pesquisas que se debruçam sobre este tema. Os temas abordados possuem uma variedade representativa de aspectos relevantes, relacionados ao cotidiano das comunidades indígenas, de pescadores artesanais e dos povos de terreiro, buscando dar visibilidade às tradições, resgatar direitos e levar para conhecimento da sociedade a história desses povos.
\end{abstract}

PALAVRAS-CHAVE: pescadores artesanais, povos indígenas, povos de terreiros.

\section{CURRENT STATUS OF RESEARCH WITH COMMUNITIES TRADITIONALS IN THE SEMIÁRID}

\section{ABSTRACT}

This article discusses the current status of research developed from the knowledge and practices of traditional communities in the semi-arid region, with a focus on indigenous peoples, terreiros and artisanal fishermen. taking into account that the semi-arid region of the Brazilian Northeast has environmental characteristics that 
impose serious limitations on the productive process of these populations, requiring them a capacity for adaptation to this environment, proposals such as this aim to identify socioeconomic, cultural and environmental aspects more investigated and those that need attention and intervention by the research and support centers, in order to support and guide the productive processes in these communities. The research was conducted in scholarly research sites, google scholar and Science direct and Scielo, using previously selected indexers. Current research on traditional peoples in the semi-arid region is quite significant, of good quality, and promotes research programs that focus on this topic. The themes covered here have a representative variety of relevant aspects related to the daily life of indigenous communities, artisanal fishermen and terreiro people, seeking to give visibility to traditions, to recover rights and to bring the history of these peoples to the knowledge of society.

KEYWORDS: artisanal fishermen, indigenous peoples, people of terreiros.

\section{INTRODUÇÃO}

Tendo como característica a seca, provocada pela escassez de chuvas (CARVALHO, 2013), o semiárido brasileiro, também denominado de terras secas, pela Convenção Mundial de Combate à Desertificação (CCD), da mesma forma que as zonas climáticas Áridas e Subúmidas Secas (ASS) do mundo, o semiárido é considerado uma Área Susceptível à Desertificação (ASD). No Brasil, as ASD foram delimitadas, em 2003, pelo Ministério do Meio Ambiente (MMA), e a partir desse mapeamento criou-se o semiárido brasileiro, incorporando 11 estados (CARVALHO, 2013).

As secas só foram consideradas um grave problema para o Brasil, a partir de 1877, com o aumento da perda dos rebanhos por mortalidade, contrariando os interesses políticos dos coronéis da época, além da possibilidade de lucrar com aquela situação de tristeza e calamidade, fazendo da seca um grande negócio, pois detinham argumentos para conseguir recursos, obras e outros benefícios que mais privilegiaria as elites dominantes locais, criando o sistema posteriormente intitulado de indústria da seca (SILVA, 2003).

Inseridos num cenário, onde, só recentemente os Povos e Comunidades Tradicionais passaram a ter políticas públicas no âmbito do Estado Brasileiro (SEPPIR, 2013). O marco inicial foi a Convenção 169 da Organização Internacional do Trabalho (OIT), que trata dos direitos dos povos indígenas e tribais no mundo (PERUZZO, 2017).

Em 2007, esse público passou a fazer parte da agenda do governo federal no Brasil, com a edição do Decreto 6040, o qual teve por objetivo instituir a Política Nacional de Desenvolvimento Sustentável dos Povos e Comunidades Tradicionais (PNPCT), sob a coordenação da Secretaria de Políticas de Promoção da Igualdade Racial (SEPPIR) da Presidência da República (BRASIL, 2018).

Os povos e comunidades tradicionais, são definidos pelo Decreto 6040/2007 como grupos culturalmente diferenciados e que se reconhecem como tais, que possuem formas próprias de organização social, que ocupam e usam territórios e recursos naturais como condição para sua reprodução cultural, social, religiosa, ancestral e econômica, utilizando conhecimentos, inovações e práticas geradas e transmitidas por tradição (BRASIL, 2007).

A partir da década de 1980, as reformas constitucionais na América Latina, trouxeram novas possibilidades que se desdobraram em novas normatividades, tendo como palavra principal a pluralidade, sempre pautada, essencialmente, nas 
experiências dos povos e comunidades tradicionais. Essa relação com o Estado tem se reconfigurado, especialmente, considerando os novos lugares assumidos pelos novos movimentos sociais que têm buscado seu potencial identitário com base em diferentes demandas, como as específicas de grupos étnicos e raciais, de minorias sexuais, de defesa do meio ambiente, entre outros. A categoria de povos e comunidades tradicionais têm se sobressaído e reunido boa parte dos movimentos sociais ao colocarem como pauta comum a defesa de territórios e do uso tradicional dos recursos naturais (FIALHO, 2011).

A proposição deste estudo foi trazer uma contribuição dos status das pesquisas com povos tradicionais no semiárido, mais especificamente povos indígenas, povos de terreiro e pescadores artesanais. A metodologia utilizada no presente artigo foi a revisão bibliográfica, pois mediante revisitação das publicações é possível situar o status atual das pesquisas com comunidades tradicionais, que foi o mote central deste trabalho. Qualquer trabalho científico inicia-se com uma pesquisa bibliográfica, partindo de publicações escritas e eletrônicas, que permitem ao pesquisador conhecer o que já se estudou sobre o assunto até então (FONSECA, 2002).

Carvalho et al. (2004) apontam que uma das principais vantagens em se fazer a pesquisa bibliográfica consiste no fato de haver uma maior liberdade do investigador na cobertura de uma gama de fenômenos muito mais abrangente do que aquela que poderia pesquisar diretamente. Esta vantagem torna-se especialmente importante no caso do problema da pesquisa requisitar dados dispersos pelo espaço e pelo tempo, como é o caso do presente estudo.

Para realizar o levantamento das publicações sobre a educação indígena foram utilizados os descritores: Povos indígenas, Povos indígenas no sertão, Povos indígenas no sertão brasileiro, Povos indígenas no Nordeste brasileiro e Povos indígenas na Bahia, a partir da base de dados Scielo e Google Acadêmico. Com recorte no período de 2009 a 2018. Foram encontrados 135 artigos, destes 120 foram excluídos, 99 por não atenderem ao tema desta pesquisa e 36 repetidos, restando 15 artigos.

Após leitura minuciosa, observou-se que 11 destes artigos, apesar de apresentarem um patamar interessante para a pesquisa com sujeitos indígenas, representava o status brasileiro e não local, o que descaracterizava as respostas aos objetivos deste trabalho. Por fim, foram selecionados cinco artigos que compuseram a amostra deste estudo.

Para os Povos de Terreiro do Semiárido Brasileiro, o levantamento bibliográfico compreendeu a produção acadêmica no período de 2008 a 2017 (Quadro 1), foram usadas como palavras-chave para a busca: Candomblé, Candomblé no semiárido Brasileiro, Candomblé no sertão, Religião de Matriz Africana, Candomblé no Sertão Brasileiro e Religião de Matriz Africana no Brasil, apenas foram considerados os textos que trataram integralmente do tema foco desta pesquisa.

Para contextualizar os estudos sobre as comunidades de pescadores artesanais no semiárido nordestino, o recorte temporal teve abrangência em estudos realizados de 2012 a 2017. A pesquisa foi realizada em sites de pesquisas acadêmicos, google scholar e Science direct e Scielo, utilizando-se como indexadores os termos "status atual da pesquisa etnográfica", "pesca artesanal" e "semiárido nordestino". Foram selecionadas pesquisas cujo tema central foi "pesca artesanal", onde estão descritos equipamentos utilizados, técnicas, estratégias de pesca, taxonomia entre outros. Foram priorizados estudos que retrataram como essa atividade tradicional 
repercute na vida de pescadores e pescadoras, seja do ponto de vista cultural, social e ou econômico.

\section{OS POVOS INDÍGENAS NO SERTÃO NORDESTINO}

Foi possível observar uma quantidade ainda pequena em publicações, já que em 10 anos de delimitação temporal, acerca da temática exposta só foram encontrados cinco trabalhos com o recorte regional pretendido. Conforme demonstrado no quadro 1, é possível notar que as publicações se concentraram nos anos de 2011, 2014, 2017, o que denota um vazio produtivo nos outros anos e uma escassez literária notável. Com relação às fontes de publicação, todas são distintas e de diversificadas áreas, o mesmo acontece com os autores.

QUADRO 1 - Produção do conhecimento sobre os povos indígenas no sertão

\begin{tabular}{l|l|c|l}
\hline \multicolumn{1}{c|}{ Título } & \multicolumn{1}{c|}{ Autor(a)/(es) } & $\begin{array}{c}\text { Ano de } \\
\text { publicação }\end{array}$ & Local de publicação \\
\hline $\begin{array}{l}\text { Índios no semiárido } \\
\text { nordestino: } \\
\text { (re)conhecendo } \\
\text { sociodiversidades }\end{array}$ & SILVA, E. & 2017 & $\begin{array}{l}\text { Revista de Pesquisa } \\
\text { Histórica }\end{array}$ \\
\hline $\begin{array}{l}\text { Um pouco além dos } \\
\text { territórios: o direito } \\
\text { fundamental dos } \\
\text { povos indígenas a } \\
\text { uma educação } \\
\text { diferenciada }\end{array}$ & $\begin{array}{l}\text { PEREIRA, P. F. S. } \\
\text { NETHO, J. }\end{array}$ & 2017 & $\begin{array}{l}\text { Revista Jurídica da } \\
\text { Presidência }\end{array}$ \\
\hline $\begin{array}{l}\text { Movimentos sociais e } \\
\text { Educação Indígena na } \\
\text { contemporaneidade - } \\
\text { as representações } \\
\text { acerca da terra e da } \\
\text { educação }\end{array}$ & SILVA, W. A. e & 2014 & $\begin{array}{l}\text { Cadernos do Tempo } \\
\text { Presente }\end{array}$ \\
\hline $\begin{array}{l}\text { Memórias indígenas: } \\
\text { novos valores para } \\
\text { uma educação }\end{array}$ & BATISTA, H. S. & 2011 & $\begin{array}{l}\text { Revista } \\
\text { Identidades }\end{array}$ \\
\hline $\begin{array}{l}\text { Etnicorracial } \\
\text { Fon }\end{array}$ & & & Fórum \\
\hline
\end{tabular}

Fonte: banco de dados dos autores.

\section{STATUS ATUAL DAS PESQUISAS COM POVOS INDÍGENAS NO SEMIÁRIDO NORDESTINO}

As pesquisas que mais se destacaram acerca dos povos indígenas, na demarcação territorial do sertão nordestino (Figura 1), teve foco na luta pela terra, pela afirmação da identidade, e por uma educação intercultural (BATISTA, 2011; SILVA; MARQUES, 2014).

Silva (2017) traz uma compreensão dos processos históricos mobilizadores das formações indígenas no semiárido nordestino, apontando para a necessidade de reconhecimento das sociodiversidades indígenas como elemento de contribuição para a elucidação das relações entre as etnias e a natureza, demarcando o papel do ambiente para estas populações. O que também é apontado por Santos et al. (2018) 
que evidenciam a importância do ambiente para afirmação das expressões socioculturais dos Truká que se mobilizaram reivindicando o direito ao território considerado sagrado.

Os estudos de Batista (2011) analisam as memórias dos professores indígenas demarcando contrapontos entre a memória ancestral indígena e a memória oficialmente aceita que se ensina nas escolas. O artigo de Batista (2011) apresenta relevância para o presente trabalho pois traça o percurso da história atual da educação indígena na Bahia e no Brasil, ponto de estudo que, se explorado, pode ir demarcando necessidades destes povos, academicamente.

Pereira e Shiraishi-Neto (2017) apontam para a existência de um compromisso com a educação diferenciada de povos indígenas, o que é mote de diversas discussões acadêmicas, inclusive nas propostas de implantação de licenciaturas específicas para o ensino em comunidades indígenas e para sujeitos dessa comunidade, academicamente inseridos.

Pode-se depreender, a partir do exposto, que as construções das pesquisas atuais acerca da educação indígena no semiárido nordestino, produzem um saber múltiplo, por tratarem de vários temas, o que visibiliza esta população. É necessário pontuar, por fim, sobre a necessidade de mais produções acadêmicas acerca desta temática, pois além de atualizar e elaborar questões ligadas aos saberes e fazeres indígenas, permitem o desenvolvimento de indagações que possam construir ou reafirmar teses importantes a serem produzidas.

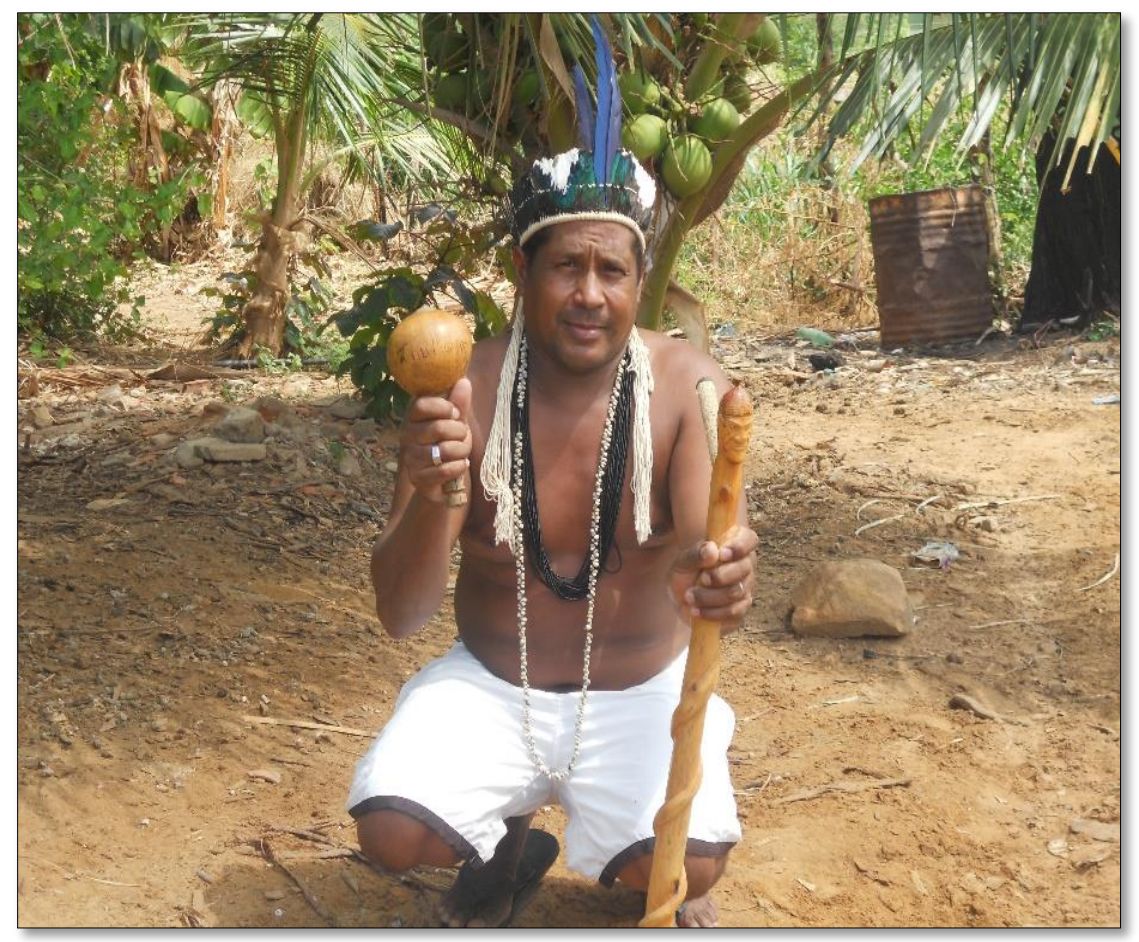

FIGURA 1: Pajé da Aldeia Coronheira, Povo Truká da Ilha de Assunção, Cabrobó/PE

Foto: By Carlos Alberto Batista Santos. CAAE: 12937913.6.1001.0057. Parecer 723.750. 


\section{OS POVOS DE TERREIRO NO SEMIÁRIDO BRASILEIRO}

Desde o período da colonização do Brasil entraram no país milhares de escravos negros, oriundos de várias partes do continente africano, que foram distribuídos de forma não planejada, estes criaram raízes e ajudaram a construir a nação. Os escravos trouxeram na bagagem mais do que a força de trabalho, muito da sua cultura imaterial que tornou-se parte do país, foi assim com a cultura e religião. Os africanos que chegaram ao Brasil oriundos de etnias variadas criaram uma forma única de se relacionarem com o divino/humano, que se traduziu nas religiões de matriz africana e no semiárido brasileiro isto não foi diferente, a partir desta constatação, percebe-se que dentro do Sertão do Brasil os espaços de Terreiro são pedacinhos de uma Diáspora Africana maior (MARQUES; NOVAIS 2015).

O semiárido brasileiro é formado por nove estados da região Nordeste (Piauí, Rio grande do Norte, Paraíba, Pernambuco, Ceará, Alagoas, Sergipe e Bahia) e um estado da região Sudeste (parte norte de Minas Gerais), englobando 1.133 municípios (BRASIL, 2017). Esta região no período da colonização serviu como porto de desembarque de escravos vindo de vários pontos da África, por isso grande parte da população é formada por descendentes de africanos, resultando na fundação de muitas casas de Candomblé de Nação, que se constituem nos espaços sagrados de culto dos Povos de Terreiro que professam a Religião de Matriz Africana, tendo no Nordeste brasileiro um cruzamento de identidades (ALVES; MARQUES, 2017).

Os negros que chegaram ao Brasil como escravos, se organizaram de forma que suas vivências na África pré-colonial fossem reproduzidas nos Terreiros. A base da vivência da comunidade é a partilha de tudo por todos, tendo uma forte ligação com a terra que é sagrada por pertencer aos Ancestrais e o território é seu maior referencial cultural, pois guarda a organização social, econômica, política e o sagrado, e seus saberes, falares e fazeres assim como suas relações com a natureza são a memória viva da África em terras brasileiras (BAHIA, 2016).

A vida destes povos em solo Brasileiro tem sido marcada por muito sofrimento e lutas desde o período da escravidão até os dias atuais, marcados pela insígnia da negatividade colocada culturalmente pela colonização europeia, têm sido vítimas cada dia mais do preconceito e do racismo, hoje traduzido em ações da chamada intolerância religiosa, no semiárido isso se traduz cotidianamente, deixando estão estes povos à margem da sociedade (SILVA et al., 2015).

\section{STATUS ATUAL DAS PESQUISAS COM POVOS TRADICIONAIS DE TERREIRO NO SEMIÁRIDO}

As pesquisas sobre os Povos e Comunidades Tradicionais de Terreiro no Semiárido Brasileiro (Figura 2) ainda são escassas, apesar de se ter notícias da presença significativa destes em toda a região semiárida (Quadro 2). 


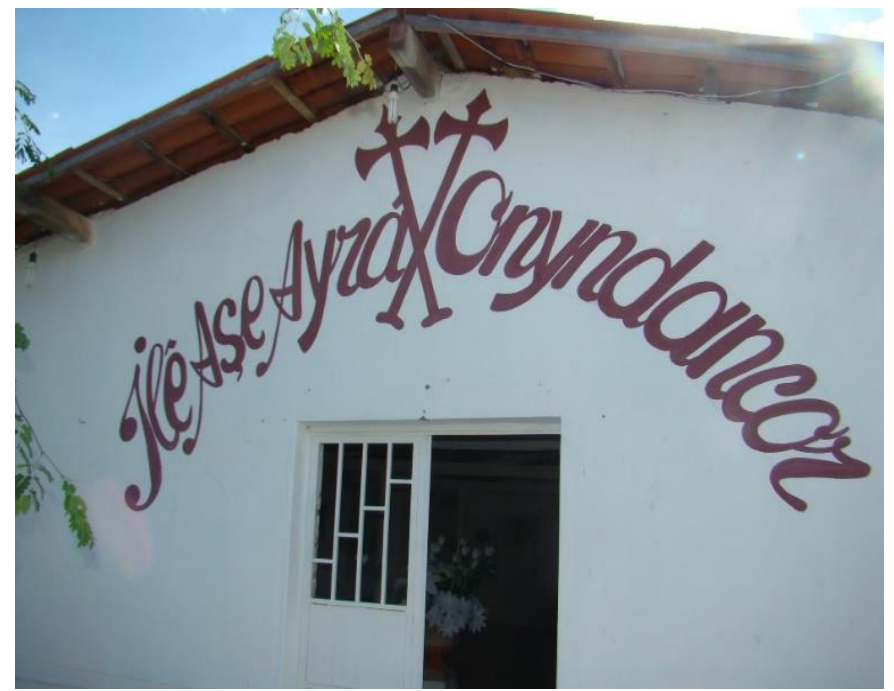

FIGURA 2: Tereiro Ilê Ase Oyrá Onyndancor, Juazeiro, Bahia, Brasil Foto: Acervo dos Autores

QUADRO 2 - Produção acadêmica referente aos Povos de Terreiro no semiárido brasileiro

\begin{tabular}{|c|c|c|c|}
\hline Título & Autores & $\begin{array}{c}\text { Ano de } \\
\text { publicação }\end{array}$ & Local de publicação \\
\hline $\begin{array}{l}\text { O silêncio dos tambores: } \\
\text { violência contra os povos } \\
\text { de terreiros no Brasil }\end{array}$ & MARQUES, J. & & $\begin{array}{l}\text { http://juracymarques.c } \\
\text { om.br/site/o-silencio- } \\
\text { dos-tambores- } \\
\text { violencia-contra-os- } \\
\text { povos-de-terreiros-no- } \\
\text { brasil/ }\end{array}$ \\
\hline $\begin{array}{l}\text { Manifestações religiosas } \\
\text { no contexto semiárido: } \\
\text { Um estudo sobre } \\
\text { hibridismo cultural e } \\
\text { territorialidade no } \\
\text { submédio São Francisco }\end{array}$ & $\begin{array}{l}\text { FLORÊNCIO, } \\
\text { R R. e } \\
\text { SANTOS, C. } \\
\text { A. B. }\end{array}$ & 2017 & $\begin{array}{l}\text { Revista Caribeña de } \\
\text { Ciencias } \\
\text { (mayo 2017). }\end{array}$ \\
\hline $\begin{array}{l}\text { A pomba-gira cigana no } \\
\text { candomblé do sertão: } \\
\text { subversões e } \\
\text { peculiaridades em } \\
\text { Maracás, Bahia }\end{array}$ & $\begin{array}{l}\text { AGUIAR, I. P. e } \\
\text { MACHADO, I. } \\
\text { K. N. }\end{array}$ & 2017 & $\begin{array}{l}\text { Odeere: revista do } \\
\text { programa de pós- } \\
\text { graduação } \\
\text { Relações Étnicas em } \\
\text { Contemporaneidade. } \\
\text { 3(3):131-152. }\end{array}$ \\
\hline A voz do Tempo & $\begin{array}{l}\text { MARQUES, J.; } \\
\text { ALVES, M. R. } \\
\text { A. e } \\
\text { MARQUES, R. }\end{array}$ & 2017 & Editora SABEH. \\
\hline
\end{tabular}




\begin{tabular}{|c|c|c|c|}
\hline $\begin{array}{l}\text { Africanidade e identidade } \\
\text { yorubá nos terreiros do } \\
\text { sertão: a força da } \\
\text { tradição oral }\end{array}$ & $\begin{array}{l}\text { ALVES, M. R. } \\
\text { A. } \\
\text { MARQUES, J. }\end{array}$ & 2017 & Revasf, 6(10):65-74. \\
\hline $\begin{array}{l}\text { A transmissão oral nos } \\
\text { terreiros de Candomblé: } \\
\text { memória e história do } \\
\text { povo descendente de } \\
\text { africanos em juazeiro-BA. }\end{array}$ & $\begin{array}{l}\text { ALVES, M. R. } \\
\text { A. SILVA, K. } \\
\text { G. O. }\end{array}$ & 2016 & $\begin{array}{lr}\text { Conidis - I } & \text { Congresso } \\
\text { Internacional } & \text { da } \\
\text { Diversidade } & \text { do } \\
\text { Semiárido. } & \text { Campina } \\
\text { Grande/PB, p. 1-12. }\end{array}$ \\
\hline $\begin{array}{l}\text { A transmissão oral como } \\
\text { dinâmica da memória e } \\
\text { construção de } \\
\text { identidades afro- } \\
\text { brasileiras }\end{array}$ & $\begin{array}{l}\text { ALVES, M. R; } \\
\text { Marques, J. }\end{array}$ & 2016 & $\begin{array}{l}\text { III Conedu - Congresso } \\
\text { Nacional de Educação. } \\
\text { Natal- } \\
\text { RN }\end{array}$ \\
\hline $\begin{array}{l}\text { Candomblé e umbanda: } \\
\text { A resistência dos } \\
\text { terreiros no médio São } \\
\text { Francisco }\end{array}$ & $\begin{array}{l}\text { ARAÚJO, D. } \\
\text { B. S.; SILVA, I. } \\
\text { M., BORGES, } \\
\text { J. J. S. e } \\
\text { MARQUES, J. }\end{array}$ & 2016 & $\begin{array}{l}\text { Os saberes populares } \\
\text { no viés da Ecologia } \\
\text { Humana. SABEH. }\end{array}$ \\
\hline $\begin{array}{l}\text { Intolerância religiosa: } \\
\text { uma análise do editorial } \\
\text { do jornal diário da região }\end{array}$ & $\begin{array}{l}\text { SILVA, I e } \\
\text { SANTOS, D. } \\
\text { A. C. }\end{array}$ & 2016 & $\begin{array}{l}\text { XXXIX Congresso } \\
\text { Brasileiro de Ciências } \\
\text { da Comunicação - São } \\
\text { Paulo. }\end{array}$ \\
\hline $\begin{array}{l}\text { Educação nos terreiros } \\
\text { de candomblé: } 0 \\
\text { aprendizado } \\
\text { dos saberes tradicionais } \\
\text { numa perspectiva de } \\
\text { ludicidade }\end{array}$ & $\begin{array}{l}\text { SILVA, A. O.; } \\
\text { SANTOS, V. } \\
\text { B.; RIOS, P. P. } \\
\text { S.; RICARDO, } \\
\text { A. e } \\
\text { VIEIRA, L. }\end{array}$ & 2015 & $\begin{array}{l}\text { Il Conedu - Congresso } \\
\text { Nacional de Educação. } \\
\text { Campina Grande-PB }\end{array}$ \\
\hline $\begin{array}{l}\text { A pele do orixá: infância, } \\
\text { educação e ecologia nos } \\
\text { terreiros de Candomblé e } \\
\text { Umbanda de Petrolina } \\
\text { (PE) e Juazeiro (BA), } \\
\text { Brasil. }\end{array}$ & 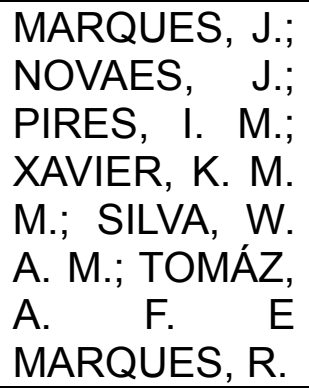 & 2015 & $\begin{array}{l}\text { Revista } \quad \text { Ecologias } \\
\text { Humanas, 1(1): 72-89. }\end{array}$ \\
\hline $\begin{array}{l}\text { Candomblé e Umbanda } \\
\text { no Sertão - Cartografia } \\
\text { Social dos Terreiros de } \\
\text { Petrolina PE e Juazeiro } \\
\text { BA }\end{array}$ & $\begin{array}{l}\text { MARQUES, J. } \\
\text { e NOVAES, J. }\end{array}$ & 2015 & Editora da SABEH. \\
\hline $\begin{array}{l}\text { Religiões afro-brasileiras: } \\
\text { estudo de caso do } \\
\text { candomblé em } \\
\text { Cajazeiras - PB }\end{array}$ & $\begin{array}{l}\text { FREITAS, J. P.; } \\
\text { MEDEIROS, } \\
\text { M. C. S.; } \\
\text { SILVA, J. A. L. } \\
\text { e SILVA NETO, } \\
\text { M. F. }\end{array}$ & 2013 & $\begin{array}{l}\text { Dimensões, } 31: 205- \\
227 .\end{array}$ \\
\hline
\end{tabular}




\begin{tabular}{|c|c|c|c|}
\hline $\begin{array}{l}\text { É Proibido Bater Tambor. } \\
\text { Candomblé em Feira de } \\
\text { Santana }(1891-1940)\end{array}$ & $\begin{array}{l}\text { SILVA, G. N. e } \\
\text { SILVA, E. }\end{array}$ & 2012 & $\begin{array}{l}\text { Anais dos Simpósios } \\
\text { da ABHR, Vol. 13, p. } \\
1-15\end{array}$ \\
\hline $\begin{array}{l}\text { Teologia da jurema. } \\
\text { Existe alguma? }\end{array}$ & $\begin{array}{l}\text { OLIVEIRA, A. } \\
\text { A. }\end{array}$ & 2011 & $\begin{array}{l}\text { V Colóquio de história- } \\
\text { Perspectivas históricas } \\
\text { historiografia, pesquisa } \\
\text { e patrimônio, p. 1084- } \\
1105 \text {. }\end{array}$ \\
\hline $\begin{array}{l}\text { A natureza sagrada do } \\
\text { candomblé: } \\
\text { Análise da construção } \\
\text { mística acerca } \\
\text { da natureza em terreiros } \\
\text { de candomblé } \\
\text { no Nordeste de brasil }\end{array}$ & $\begin{array}{l}\text { LÉO NETO, N. } \\
\text { A. e ALVES, R. } \\
\text { R. N. }\end{array}$ & 2010 & $\begin{array}{l}\text { Interciencia - Red. de } \\
\text { Revistas Científicas de } \\
\text { América Latina y el } \\
\text { Caribe, España y } \\
\text { Portugal, 35(8):568- } \\
574 .\end{array}$ \\
\hline $\begin{array}{l}\text { Candomblé e Umbanda } \\
\text { no Sertão - Cartografia } \\
\text { Social dos terreiros de } \\
\text { Jaguarari }\end{array}$ & $\begin{array}{l}\text { ALMEIDA, A. } \\
\text { W. B. e } \\
\text { MARQUES, J. }\end{array}$ & 2010 & $\begin{array}{l}\text { Relatório de Atividades } \\
\text { LAPEC/NECTAS. } \\
\text { Manaus: EEA, } \\
\text { (Coleção Povos de } \\
\text { Terreiro). }\end{array}$ \\
\hline $\begin{array}{l}\text { Candomblé e Umbanda } \\
\text { no Sertão - } \\
\text { Cartografia Social } \\
\text { dos terreiros de Paulo } \\
\text { Afonso }\end{array}$ & $\begin{array}{l}\text { MARQUES, J. } \\
\text { e } \\
\text { FERNANDES, } \\
\text { F. M. S. }\end{array}$ & 2009 & $\begin{array}{l}\text { Relatório de } \\
\text { Atividades: Candomblé } \\
\text { e Umbanda no Sertão } \\
\text { Cartografia Social dos } \\
\text { Terreiros de Paulo } \\
\text { Afonso }\end{array}$ \\
\hline $\begin{array}{l}\text { As Religiões Afro- } \\
\text { Brasileiras na Voz das } \\
\text { Mulheres Lideranças em } \\
\text { Juazeiro do Norte }\end{array}$ & $\begin{array}{l}\text { SILVA, J.e } \\
\text { DOMINGOS, } \\
\text { R. F. }\end{array}$ & 2009 & $\begin{array}{l}\text { Revista } \\
\text { Ciência, 16(31): 111- } \\
\text { 124. }\end{array}$ \\
\hline $\begin{array}{l}\text { Plantas medicinais: sua } \\
\text { utilização nos terreiros de } \\
\text { umbanda e candomblé } \\
\text { na zona leste de cidade } \\
\text { de Campina Grande-PB }\end{array}$ & $\begin{array}{l}\text { GOMES, H. H. } \\
\text { S.; } \\
\text { DANTAS, I. C. } \\
\text { e } \\
\text { CATÃO, M. H. } \\
\text { C. V. }\end{array}$ & 2008 & $\begin{array}{l}\text { Revista de Bioquímica } \\
\text { e farmácia, 03(01):110- } \\
129 .\end{array}$ \\
\hline
\end{tabular}

Os Povos e Comunidades Tradicionais de Terreiro do Semiárido enfrentam muitos desafios como o acesso a Políticas Públicas estruturantes, certificação de seus espaços sagrados, combate efetivo do Racismo Religioso entre outros, o crescimento de publicações sobre estes Povos servirá de forte reforço em suas lutas (BRASIL, 2007).

\section{PESCA ARTESANAL NO SEMIÁRIDO BRASILEIRO}

Para Marques (2012), a etnoictiologia é o estudo das interações entre os seres humanos e os peixes. O autor enfatiza que a relação entre homens e peixes não se resume a uma relação entre o predador e a presa, uma vez que esse fenômeno possui uma complexa relação simbólica reveladora de valores e significados presentes na 
cadeia trófico-cultural. Essa interação, por vezes, fortalece a relação entre homens e peixes, e por vezes, provoca repulsas e tabus.

Cercado de misticismos, os peixes por habitarem os espaços dos seres encantados (LUCIANO, 2006), estão cercados de emoções e sentimentos que interferem na sua utilização, a exemplo da mulher que pariu recentemente, que deve se alimentar de peixes não carregados como o piau (Leporinus cf piau Fowler, 1941) e a traíra (Hoplias malabaricus Bloch, 1794). Oliveira (2004) relata entre outros ditos populares que "peixe engolido vivo ensina a nadar", e "nenhum resultado se consegue em pescaria durante trovoada, pois os peixes se escondem", pelas margens do Rio São Francisco registrou entre tantas crendices, que a traíra transforma-se em serpente em noite de lua cheia.

Além das crendices e da alimentação, o peixe entre as populações do semiárido nordestino é utilizado na cura de enfermidades (EL-DEIR et al., 2012; FERREIRA et al., 2013; SANTOS; ALVES, 2016), constituindo-se um importante elemento da medicina tradicional popular nesta região.

\section{STATUS ATUAL DAS PESQUISAS SOBRE COMUNIDADES DE PESCADORES TRADICIONAIS NO SEMIÁRIDO}

O Brasil possui uma das mais extensas áreas propicias à pesca do mundo. A longa costa marítima, os numerosos rios, lagos e reservatórios permitem que a atividade pesqueira se desenvolva, tanto em águas oceânicas quanto em águas continentais. Esse gigantesco volume de água, garante ao Brasil uma condição privilegiada para a prática da pesca artesanal (SANTOS et al., 2012). A região Nordeste reflete essas mesmas características da geografia brasileira, abrigando uma longa área costeira, ao mesmo tempo em que possui importantes bacias hidrográficas, entre estas a bacia do rio São Francisco, a mais importante em extensão e volume d'agua a banhar o semiárido nordestino (citação).

O Nordeste contém $18 \%$ das bacias hidrográficas brasileiras, e por esse motivo essa região registra a ocorrência de diversas modalidades de pesca sendo a mais comum, no semiárido, a pesca artesanal. Esta é praticada sobretudo como atividade de subsistência, utiliza-se de técnicas consideradas tradicionais (DIEGUES, 1983). Sendo assim, muitos grupos humanos têm na pesca artesanal a principal fonte de alimentação e renda (Figura 3). Além das bacias do rio São Francisco e do rio Parnaíba, outras bacias de menor porte, lagos e reservatórios formam os territórios pesqueiros do semiárido nordestino. A pesca artesanal existente nesses territórios será o objeto de estudo desse trabalho (FREITAS et al., 2015). 


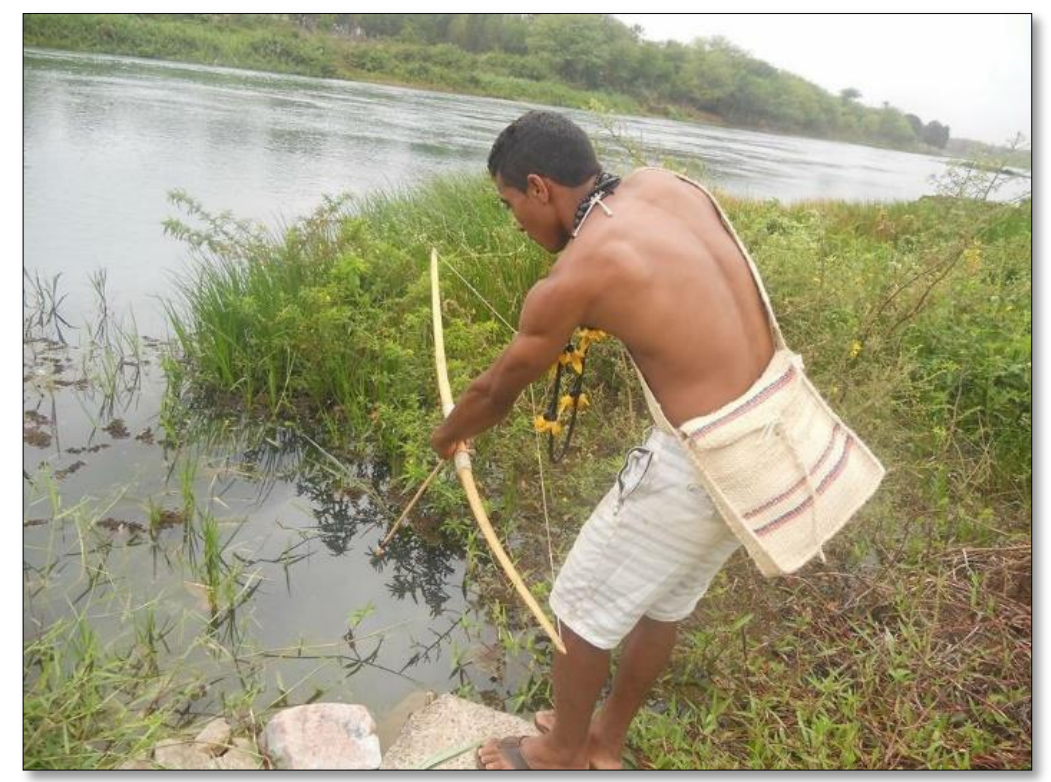

FIGURA 3: Pescador Indígena Truká, Território Indígena Ilha de Assunção, Aldeia Coronheira, Cabrobó/PE

Foto: By Carlos Alberto Batista Santos. CAAE: 12937913.6.1001.0057. Parecer 723.750.

Os estudos que apresentam uma visão geral da Etnoictologia, e a originalidade da comparação cognitiva entre a ciência nativa e a ciência ocidental; Estudos com foco nas características geográficas do rio, questões sobre a prática da pesca artesanal e dos fatores antrópicos que interferem nos processos da pesca, e muitos diagnósticos da Pesca Artesanal são realizados, entre estes o de Novaes e colaboradores (2015) e Santos e Alves (2016). O quadro 3 traz um apanhado dos trabalhos mais recentes sobre a pesca artesanal no semiárido nordestino.

QUADRO 3 - Produção acadêmica referente às comunidades de pescadores artesanais no semiárido brasileiro

\begin{tabular}{|c|c|c|c|}
\hline Título & Autores & Ano & Local de publicação \\
\hline $\begin{array}{l}\text { Etnoictiologia: } \\
\text { pescando } \\
\text { pescadores nas } \\
\text { aguas da } \\
\text { transdisciplinaridade. }\end{array}$ & $\begin{array}{l}\text { MARQUES, J. G. } \\
\text { W. }\end{array}$ & 2012 & $\begin{array}{l}\text { Revista } \text { Ouricuri, } \\
\text { Afonso, v. 2, n. 2, p. 9-36, } \\
\text { jul./dez. }\end{array}$ \\
\hline $\begin{array}{l}\text { Balanço histórico das } \\
\text { lutas dos pescadores } \\
\text { artesanais em Per- } \\
\text { nambuco: } \\
\text { Algumas questões } \\
\text { para o debate. }\end{array}$ & $\begin{array}{l}\text { RAMALHO, C. W. } \\
\text { N. }\end{array}$ & 2012 & $\begin{array}{l}5^{0} \text { Encontro da Rede de } \\
\text { Estudos Rurais }\end{array}$ \\
\hline $\begin{array}{l}\text { Território da pesca e } \\
\text { aquicultura: A experi- } \\
\text { ência do Asuu - Mos- } \\
\text { soró no semiárido } \\
\text { Potiguar. }\end{array}$ & $\begin{array}{lr}\text { MAIA, I. } & \text { S.; } \\
\text { OLIVEIRA } & \text { NETO, } \\
\text { J. T.; } & \text { BESSA } \\
\text { JÚNIOR, } & \text { A. P. }\end{array}$ & 2012. & $\begin{array}{l}\text { Seminário Nacional de } \\
\text { Geologia e Planejamento } \\
\text { Territorial. }\end{array}$ \\
\hline
\end{tabular}




\begin{tabular}{|c|c|c|c|}
\hline $\begin{array}{l}\text { Diagnóstico da Pesca } \\
\text { Artesanal em um } \\
\text { Reservatório do } \\
\text { Semiárido Brasileiro. }\end{array}$ & $\begin{array}{l}\text { NOVAES, J.L.C; } \\
\text { FREIRE, A. E.; } \\
\text { AMORIM, R. R. A.; } \\
\text { COSTA, R. S. }\end{array}$ & 2015 & $\begin{array}{l}\text { Bol. Inst. Pesca, São Paulo, } \\
\text { 41(1): } 31-42 \text {. }\end{array}$ \\
\hline $\begin{array}{l}\text { Conflitos socioambi- } \\
\text { entais da pesca arte- } \\
\text { sanal no } \\
\text { Nordeste do Brasil. }\end{array}$ & $\begin{array}{l}\text { CARVALHO } \\
\text { NETO, M. F. } \\
\text { SILVA, L. C. M. }\end{array}$ & 2015. & $\begin{array}{l}\text { Cadernos de agroecologia, } \\
\text { v.10, n. } 3 \text {. }\end{array}$ \\
\hline $\begin{array}{l}\text { Problemas socioam- } \\
\text { bientais a pesca arte- } \\
\text { sanal no Nordeste do } \\
\text { Brasil. } 5\end{array}$ & $\begin{array}{l}\text { SILVA, L. C. M; } \\
\text { NETO, N. F. C. }\end{array}$ & 2015 & $\begin{array}{l}\text { Revista de Extensão da } \\
\text { Univasf. v. 3, n.2, p.189-20. }\end{array}$ \\
\hline $\begin{array}{l}\text { Ethnoichthyology of } \\
\text { the indigenous Truká } \\
\text { people, Northeast } \\
\text { Brazil. }\end{array}$ & $\begin{array}{l}\text { SANTOS, C. A. B.; } \\
\text { ALVES, R. R. N. }\end{array}$ & 2016 & $\begin{array}{l}\text { Journal of ethnobiology and } \\
\text { ethnomedicine, v. } 12, \text { n. } 1, p \text {. } \\
1\end{array}$ \\
\hline $\begin{array}{l}\text { Conhecimento ecoló- } \\
\text { gico tradicional, uso e } \\
\text { manejo dos } \\
\text { Peixes na região do } \\
\text { submédio São } \\
\text { Francisco }\end{array}$ & $\begin{array}{l}\text { SANTOS, K. S. S.; } \\
\text { SANTOS, C. A. B. }\end{array}$ & 2016 & $\begin{array}{l}\text { I Congresso Internacional da } \\
\text { Diversidade do Semiárido } \\
\text { (CONIDIS). } \\
\text { Grande/PB, p. 1-10. }\end{array}$ \\
\hline $\begin{array}{l}\text { Aspectos } \\
\text { Socioambientais da } \\
\text { Pesca Artesanal no } \\
\text { Submédio São } \\
\text { Francisco }\end{array}$ & $\begin{array}{l}\text { SANTOS, K. S. S.; } \\
\text { SANTOS, C. A. B. }\end{array}$ & 2017 & $\begin{array}{l}\text { II Congresso Internacional da } \\
\text { Diversidade do Semiárido } \\
\text { (CONIDIS). } \\
\text { Grande/PB, p. 1-10. }\end{array}$ \\
\hline $\begin{array}{l}\text { Aspectos socioambi- } \\
\text { entales de la pesque- } \\
\text { ría artesanal } \\
\text { Brasileña: un } \\
\text { enfoque de las } \\
\text { literaturas }\end{array}$ & $\begin{array}{l}\text { AMARAL, D. F.; } \\
\text { SANTOS, C. A. B.; } \\
\text { SILVA, T. A. }\end{array}$ & 2017 & $\begin{array}{l}\text { Revista Contribuciones a las } \\
\text { Ciencias Sociales, (octubre- } \\
\text { diciembre 2017). }\end{array}$ \\
\hline
\end{tabular}

\section{CONSIDERAÇÕES FINAIS}

As pesquisas atuais sobre os Povos Indígenas no semiárido, são bem significativas, de muito boa qualidade, porém há um caminho muito amplo ainda a ser percorrido para que se respeite efetivamente todos os direitos destes povos, como o direito a uma educação intercultural gratuita e de qualidade.

A produção atual de conhecimento sobre os Povos de Terreiro no Semiárido ainda é tímida. O foco das pesquisas tem se voltado principalmente para a forma de vida destes povos e seus rituais a partir das especificidades de cada nação, sendo bem fundamentado e de fácil leitura, percebemos que isso se deve principalmente ao olhar cada vez maior que as Universidades principalmente os núcleos que se 
encontram no semiárido tem tido sobre as questões relacionadas aos Povos de Terreiro, suas lutas e especificidades fomentando programas de pesquisas que se debruçam sobre este tema.

Acreditamos que a adoção do recorte temático nos permitiu apresentar uma variedade mais representativa de aspectos relevantes, relacionados ao cotidiano dos trabalhadores da pesca artesanal, no semiárido nordestino.

Para as comunidades de pescadores artesanais, pelo levantamento efetuado, chegamos à conclusão que há uma preocupação dos meios acadêmicos com um incentivo da pesquisa com os povos tradicionais, visando cada vez mais resgatar direitos, tradições e levar a sociedade em geral o conhecimento da verdadeira história desses povos.

\section{REFERÊNCIAS}

ALVES, M. R. A.; MARQUES, J. Africanidade e identidade yorubá nos terreiros do sertão: a força da tradição oral. Revista de Educação do Vale do São Francisco, v. 6, p. 1-10, 2017.

\section{BAHIA. Plano Estadual de Desenvolvimento Sustentável dos Povos e Comunidades Tradicionais. 2016, p. 59. Disponível em: http://www.seppir.gov.br/portal-antigo/arquivos-pdf/plano-nacional-de- desenvolvimento-sustentavel-dos-povos-e-comunidades-tradicionais-de-matriz- africana.pdf/view. Acessado em 15 de janeiro de 2019.}

BATISTA, H. S. Memórias indígenas: novos valores para uma educação etnicorracial. Revista Fórum Identidades, v. 10, 2011. Disponível em: https://seer.ufs.br/index.php/forumidentidades/article/viewFile/1921/1677. Acesso em 12 novembro de 2018.

BRASIL. Decreto $n^{\circ}$ 6.040, de 7 de fevereiro de 2007. Institui a Política Nacional de Desenvolvimento Sustentável dos Povos e Comunidades Tradicionais. 2007. Disponivel em: http://www.planalto.gov.br/ccivil_03/_ato2007-2010/2007/decreto/d6040.htm. Acessado em 10 de Janeiro de 2019.

BRASIL. Ministério da Integração Nacional. Nova Delimitação do Semiárido Brasileiro, 2017. Disponível em: http://www.mi.gov.br/c/document_library/get_file?uuid=0aa2b9b5-aa4d-4b55-a6e1-82faf0762763\&groupld=24915. Acessado em 10 de Janeiro de 2019.

BRASIL. Comunidades Tradicionais - O que são. Brasília, 2018. Disponível em: http://www.seppir.gov.br/comunidades-tradicionais/o-que-sao-comunidadestradicionais. Acesso em 12 dezembro de 2018.

CARVALHO, D.; CARNEIRO, R.; MARTINS, H. F. A.; SARTORATO, E. Pesquisa Bibliográfica. Goiânia, 2004. Disponível em: http://pesquisabibliografica.blogspot.com.br. Acesso em 23 dezembro 2018.

CARVALHO, L. D. Natureza, Território e Convivência: Novas Territorialidade no Semiárido Brasileiro. Jundiaí, SP: Paco Editorial, 2013. 
DIEGUES, C. A. Pescadores, Camponeses e Trabalhadores do Mar. São Paulo: Ática, 1983.

EL-DEIR, A. C. A, COLlieR, C. A., ALMEIDA NETO, M. S., SILVA, K. M. S., POLICARPO, I. S., et al.,; Ichthyofauna Used in Traditional Medicine in Brazil. Evidence-Based Complementary and Alternative Medicine, v. 2012, p. 1-16 Disponível em: file:///C:/Users/Usu\%C3\%A1rio/Downloads/474716.pdf. Acesso em 16 de janeiro de 2019. DOI:10.1155/2012/474716.

FERREIRA, F. S.; FERNANDES-FERREIRA, H.; LEO NETO, N. BRITO, S. V.; ALVES, R. R. N. The trade of medicinal animals in Brazil: current status and perspectives. Biodiversity and Conservation, v. 22, n. 4, p. 839-870, 2013. Disponivel em: https://link.springer.com/article/10.1007/s10531-013-0475-7. Acessado em 14 de setembro de 2018. DOI: https://doi.org/10.1007/s10531-013-0475-7.

FIALHO, V. Povos Tradicionais no Sertão Semiárido: uma leitura a partir do princípio da pluralidade. Revista Coletiva, n. 6, 2011. Disponível em: http://www.coletiva.org/index.php/artigo/povos-tradicionais-no-sertao-semiarido-umaleitura-a-partir-do-principio-da-pluralidade/. Acesso em 20 novembro de 2018.

FONSECA, J. J. S. Metodologia da pesquisa científica. Fortaleza: UEC, 2002.

FREITAS, L. O.; NOGUEIRA, E. M. S.; MOURA, G. J. B. Pesca artesanal no cânion do rio São Francisco: modo de vida, desafios e percepções. In: NOGUEIRA, E. M. S.; PEREIRA DE SÁ, M. F. (orgs.) A pesca artesanal no baixo São Francisco: atores, recursos, conflitos. Petrolina, PE: SABEH, Editora da Sociedade Brasileira de Ecologia Humana, 2015. 220 p.

LUCIANO, G. S. O Índio Brasileiro: o que voce precise saber sobre os índios no Brasil de hoje. Ministério da Educação, Secretaria de Educação Continuada, Alfabetização e Diversidade. Brasília: Laced/Museu Nacional. 2006. 224p.

MARQUES, J. G. W. Etnoictiologia: pescando pescadores nas aguas da transdisciplinaridade. Revista Ouricuri, Paulo Afonso, v. 2, n. 2, p. 9-36, jul./dez. 2012. Disponível em: https://www.redalyc.org/articulo.oa? id=18126163007. Acessado em: 30 de novembro de 2018. DOI: http://dx.doi.org/10.5209/rev_NOMA.2012.41773.

MARQUES. J., NOVAIS. J. Candomblé e Umbanda no Sertão - Cartografia Social dos Terreiros de Petrolina PE e Juazeiro BA. Paulo Afonso/BA: Editora da SABEH, 2015.

OLIVEIRA, J. P. A Viagem de Volta: etnicidade, política e reelaboração cultural no Nordeste indígena. Rio de Janeiro: Contra Capa Livraria - LACED. 2004.

NOVAES, J. L. C; FREIRE, A. E.; AMORIM, R. R. A.; COSTA, R. S. Diagnóstico da Pesca Artesanal em um Reservatório do Semiárido Brasileiro. Boletim Instituto de Pesca, v. 41, n. 1, p. 31 - 42, 2015. Disponível em: 
http://www.pesca.agricultura.sp.gov.br/41_1_31-42.pdf. Acessado em: 20 de outubro de 2018.

PEREIRA, P. P. S.; SHIRAISHI-NETO, J. Um pouco além dos territórios: o direito fundamental dos povos indígenas a uma educação diferenciada. Revista Jurídica da Presidência, v. 118, n. 116, 2017. Disponível em: http://www.egov.ufsc.br/portal/sites/default/files/1238-3280-1-pb.pdf. Acesso em 12 novembro de 2018. DOI: https://doi.org/10.12957/rfd.2017.15571.

PERUZZO, P. P. Direito à consulta prévia aos povos indígenas no Brasil. Revista Direito e Práxis. Rio de Janeiro, Vol. 08, N. 04, 2017, p. 2708-2740. DOl: 10.1590/2179-8966/2017/24631| ISSN: 2179-8966

SANTOS, Marco Pais Neves dos et al. A Pesca enquanto Atividade Humana: Pesca Artesanal e Sustentabilidade. Revista de Gestão Costeira Integrada, Lisboa, v. 12, n. 4, p. 405-427, 2012. Disponível em http://www.scielo.mec.pt/sc ielo.php?script=sci_arttext\&pid=S1646-88722012000400002\&Ing=pt\&nrm=iso.

Acesso em 01 jul. 2019.

SANTOS, C. A. B.; SILVA, E. H.; OLIVEIRA, E. G. S. História ambiental, história indígena e relações socioambientais no semiárido brasileiro. Paulo Afonso: SABEH, 2018.

SANTOS, C. A. B.; ALVES, R. R. N. Ethnoichthyology of the indigenous Truká people, Northeast Brazil. Journal of Ethnobiology and Ethnomedicine, v. 12, n. 1, p. 1, 2016. Disponivel em; https://ethnobiomed.biomedcentral.com/articles/10.1186/s13002-0150076-5. Acessado em 22 de dezembro de 2018. DOI: https://doi.org/10.1186/s13002015-0076-5.

SANTOS, K. S. S.; SANTOS, C. A. B. Aspectos Socioambientais da Pesca Artesanal no Submédio São Francisco. 2017. In: II Congresso Internacional da Diversidade do Semiárido. Disponível em: http://www.editorarealize.com.br/revistas/conidis/trabalhos/TRABALHO_EV074_MD1 _SA2_ID2287_23102017235039.pdf. Acessado em: 20 de dezembro de 2018.

SECRETARIA DE POLÍTICAS DE PROMOÇÃO DA IGUALDADE RACIAL - SEPPIR. Plano Nacional de Desenvolvimento Sustentável de Povos e Comunidades Tradicionais de Matriz Africana. $1^{\text {a }}$ edição, Brasília/DF. 2013.

SILVA, A. O.; SANTOS, V. B.; RIOS, P. P. S.; RICARDO, A.; VIEIRA, L. Educação nos terreiros de candomblé: o aprendizado dos saberes tradicionais numa perspectiva de ludicidade. In. Anais...: II Congresso Nacional de Educação. V. 1, p. 2-14, 2015. Disponível em: https://www.editorarealize.com.br/revistas/conedu/. Acesso em: 20 de dezembro de 2018.

SILVA, I; ARAÚJO, D; SANTOS, C. Intolerância Religiosa: Uma análise do editorial do jornal Diário da Região. Disponível em: file://C:/Users/Admin/Downloads/Intoler\%C3\%A2ncia\%20Religiosa_\%20Uma\%20an 
\%C3\%A1lise\%20do\%20editorial\%20do\%20jornal\%20Di\%C3\%A1rio\%20da\%20Regi \%C3\%A3o\%201.pdf. Acessado em 22 de outubro de 2018.

SILVA, R. M. A. Entre dois Paradigmas: Combate a seca e convivência com o Semiárido. Sociedade e Estado, v. 18, n. 1/2, p. 361-385, 2003. Disponível em: http://www.scielo.br/scielo.php?script=sci_arttext\&pid=S0102-69922003000100017. Acessado em 10 de janeiro de 2019. DOI: http://dx.doi.org/10.1590/S010269922003000100017.

SILVA, E. Índios no semiárido nordestino: (re)conhecendo sociodiversidades. Clio Revista de Pesquisa Histórica, n. 35, p. 254-272, 2017. Disponível em: https://periodicos.ufpe.br/revistas/revistaclio/article/view/24540. Acesso em 12 outubro de 2018.

SILVA, W. A.; SANTOS, J. M. Movimentos sociais e Educação Indígena na contemporaneidade - as representações acerca da terra e da educação. Cadernos do Tempo Presente, n. 18, 2015. Disponível em: https://seer.ufs.br/index.php/tempo/article/viewFile/2997/2916. Acesso em 12 novembro de 2018.

SILVA, W. A; MARQUES, J. Povoado Cruz - contribuições aos estudos dos quilombos. Revista Gestão Acadêmica, v. 1, p. 129-142, 2014. 